\title{
Clinical Effects of Negative Pressure Wound Therapy and Basic Fibroblast Growth Factor in Patients with Pressure Ulcers
}

\author{
Seung Ki Ahn, Hwan Jun Choi, Jung Ki Kim, Jun Hyuk Kim, Young Man Lee \\ Department of Plastic and Reconstructive Surgery, College of Medicine, Soonchunhyang University, Cheonan, Korea
}

\begin{abstract}
Background: Several recent studies have focused on negative pressure wound therapy (NPWT) and its effect on pressure ulcers. Basic fibroblast growth factors (bFGF) promote the formation of granulation tissue and new blood vessels, thereby facilitating wound healing. We sought to determine and compare the efficacy and safety of NPWT combination therapy with bFGF and NPWT.

Methods: We evaluated 20 cases of pressure sores in 15 patients from December 2012 to January 2014. The patients had stage 3 or stage 4 pressure ulcers without necrosis or inflammatory tissue. NPWT only was used in the control group (CG), while NPWT and bFGF were used in the experimental group (EG). Comparisons in each group involved the amount and rate of change of the size and volume of pressure ulcers before and after treatment, and during treatment. Results: Changes in volume according to size (volume/size) were $1.10 \pm 0.78$ for the $E G$ and $0.41 \pm 0.30$ for the CG. Changes in $E G$ volume were statistically greater than those in size $(P=0.012)$.

Conclusion: Although no difference was seen in size for each period, changes in volume were significant. CG showed a significant difference during the 3rd and 4th weeks, and EG during the 2nd to 4th weeks. This indicates that the parallel use of bFGF and NPWT can reduce the volume of pressure ulcers more quickly than the use of only NPWT.
\end{abstract}

Keywords: Negative pressure wound therapy, Fibroblast growth factor2, Pressure sore, Pressure ulcer

\section{Introduction}

A pressure ulcer is caused by excessive pressure on a body part where bones protrude. This pressure causes tissue ischemia and disturbs delivery of oxygen and nutrition to tissues. This mechanism can lead to irrecoverable ischemia and tissue necrosis, ultimately leading to tissue ulcers and the formation of pressure ulcers. Maklebust defined pressure as a perpendicular load or force exerted on a unit of area [1]. Blood circulation is recovered in the area, causing reperfusion damage, and thus damaging even more tissues. In 1999, Amlung et al. [2] reported 42,817 patients of 356 organizations who had pressure ulcers based on documents. The overall pressure ulcer prevalence was $14.8 \%$, while the organization-related prevalence was $7.1 \%$. After 10 years, VanGilder et al. [3] argued that the overall prevalence was $12.3 \%$ and the organization-related prevalence was $5 \%$ according to research findings from the International Pressure Ulcer Prevalence Survey (IPUSPS).

Various methods have been used to study the treatment of patients with pressure ulcers, with negative pressure wound therapy (NPWT) as one of these advanced treatment options. Several studies have recently shown that using NPWT is significantly effective method in treating patients with pressure ulcers [4,5]. An appropriately sized polyurethane foam is placed on the wound during NPWT, the dressing

Original Article

Received: February 6, 2018

Revised: February 11, 2018

Accepted: February 12, 2018

Corresponding author:

Hwan Jun Choi, M.D., Ph.D.

Department of Plastic and Reconstructive surgery, Soonchunhyang University, Cheonan Hospital, 31 Suncheonhyang 6-gil, Dongnamgu, Cheonan 31151, Korea

Tel: +82-41-570-2195

Fax: +82-41-574-6133

E-mail: medi619@hanmail.net

This is an Open Access article distributed under the terms of the Creative Commons Attribution Non-Commercial License (http://creativecommons.org/licenses/by-nc/4.0/) which permits unrestricted non-commercial use, distribution, and reproduction in any medium, provided the original work is properly cited.

(c) 2018 Korean Wound Management Society
} 
area is molded with a film, and negative pressure is exerted on the area using a machine. The negative pressure is maintained through the film dressing, which is semi-permeable to maintain moisture in the wound area and facilitate recovery [6]. NPWT also creates an environment where aerobic bacteria do not have a sufficient amount of oxygen to survive. In addition, it facilitates blood circulation, the formation of granulation tissues, and controls the expression of inflammatory cytokines and other proteins. Moreover, the therapy removes edema and promotes blood circulation to accelerate wound recovery $[7,8]$. With such beneficial mechanisms, NPWT remarkably reduces wound recovery time, compared with other conventional wound treatment methods [9].

Basic fibroblast growth factors (bFGF) are a single-chain polypeptide with a 17,000 -dalton molecular weight that stimulates fibroblast proliferation [10]. bFGF plays a role in the inflammation, proliferation, and remodeling periods of the wound healing stage via bFGF receptors. Moreover, it accelerates keratinocyte formation in the remodeling stage, which leads to granulation tissue formation [11].

We included patients with stage 3-4 ulcers based on the National Pressure Ulcer Advisory Panel (NPUAP; 2007) classification of pressure ulcers [12]. The purpose of this study was to determine and compare the efficacy and safety of NPWT, which is used for treating pressure ulcers worldwide, with a combination therapy that uses bFGF Fiblast spray ${ }^{\circledR}$ (Kaken Pharmaceutical Co. Ltd, Tokyo, Japan) and NPWT (CuraVAC ${ }^{\circledR}$, CGBio, Seongnam, Korea). The control group (CG) included those treated with NPWT only, while the experimental group (EG) included those treated with NPWT and bFGF.

\section{Methods}

\section{Patients and Data Collection}

The study was approved by the Institutional Review Board of Soon Chun Hyang University Hospital (Approval No. 201253) and all patients provided written informed consent before enrolling. We examined 20 pressure ulcer cases in 15 patients from December 2012 to January 2014. The subjects were at least 18 years old with stage 3-4 pressure ulcers based on NPUAP (2007) classification, with no necrosis or infected tissues. Table 1 describes the inclusion and exclusion criteria for the research subjects. For four weeks, 12 subjects in the EG received NPWT and a Fiblast ${ }^{\circledR}$ spray, while eight subjects in the CG received only NPWT. To prevent possible bias in group allocation and enhance their comparability, the subjects were randomized to each group. Their visits were scheduled in the first, second, third, and fourth weeks after the initial visit. We checked the number of dressing changes for their NPWT during each visit, as well as the number of Fiblast ${ }^{\circledR}$ sprays, and the size and volume of the pressure ulcers.

\section{Medical device application}

For NPWT, ulcers were first cleaned with sterilized physiological saline and cleansed with gauze. The Fiblast ${ }^{\circledR}$ spray was then applied at a distance of $5 \mathrm{~cm}$ from the ulcer until it was fully covered. After 60 seconds, polyurethane foam was applied to the ulcer using a size corresponding to that of the ul-

Table 1. Inclusion and exclusion criteria

\begin{tabular}{ll}
\hline Inclusion criteria & \multicolumn{1}{c}{ Exclusion criteria } \\
\hline $\begin{array}{l}\text { Patients aged } 18 \text { or older } \\
\text { Patients with at least 3-stage pressure ulcer under the }\end{array}$ & $\begin{array}{l}\text { Pregnant or breast-feeding women } \\
\text { NPUAP (2007) classification }\end{array}$ \\
$\begin{array}{l}\text { Pressure ulcer patients without any necrosis and } \\
\text { infected tissue (soft tissue, osseous }\end{array}$ & Patients who have received a growth factor injection into a target ulcer \\
tissue) after debridement & screening day \\
Patients agreed in writing to participate in this & Patients diagnosed with vascular circulatory failure, ulcer accompanying cardiac \\
research experiment & arrhythmia thrombus, etc. and venous insufficiency \\
& Patients with the record of malignant tumor and malignant diseases \\
& Patients who seemed to have a shorter life expectation \\
& Patients receiving immunosuppressant treatment, radiation therapy and chemo therapy \\
& Patients who have experienced any side effect due to the research treatment above \\
& Patients with a mental disease or alcohol addiction \\
Patients who have participated in another medicine experiment at least 30 days & before this research \\
Patients who seemed to have a difficulty in following this clinical research
\end{tabular}


cer. NPWT was performed using Curasys ${ }^{\circledR}$ (Daewoong Co. Ltd, Seoul, Korea) on the -125 to $-50 \mathrm{mmHg}$ pressure in cyclic mode. The dressing was changed three times per week. CG followed the same steps with the exception of the Fiblast ${ }^{\circledR}$ spray. This clinical experiment lasted four weeks in the longest case. If the pressure ulcers were completely cured or referred for surgery within that period, the therapy was terminated early.

\section{Wound evaluation}

The size (wound surface area) and volume of pressure ulcers was measured during each patient's visit. The wound surface area and volume were calculated by measuring the longest horizontal axis, the longest vertical axis perpendicular to the horizontal axis with a flexible ruler, and the deepest height. After each measurement, the results were obtained according to Xakellis and Frantz's method (22), using the following formulas:

Wound surface area $=$ length $\times$ width $\times 0.783$

Wound volume $=$ area $\times$ depth $\times 0.327$

The measurements were used to compare the pre- and post-treatment changes in ulcer size and volume, and the change rate and amount of change in the volume/size. Changes in ulcer size and volume were examined according to the treatment period (first, second, third, and fourth weeks) from the baseline status. In addition, we checked the ratio of patients who experienced at least a $50 \%$ reduction in pressure ulcer volume before and after treatment as well as points in the treatment period when the pressure ulcer volume decreased by $50 \%$ or more in the two groups.

\section{Statistical Analysis}

Measurements were calculated as averages and standard deviations. The Mann-Whitney $U$ test was used to compare the pre- and post-treatment changes and rates of change in the size and volume between the CG and EG. The paired ttest was used to verify any significant differences in the size and volume changes in both groups according to specific periods. The chi-square test was used to compare the gap in the ratios of patients experiencing a 50\% or more reduction in pressure ulcer volume between the EG and CG after four weeks of treatment. The log-rank test was used to compare the time cost for a $50 \%$ pressure ulcer decrease, compared with baseline. Statistical significance was set at $\mathrm{P}<0.05$. For subjects who dropped out during the study, the point at which they dropped out was treated as truncated data, and for those who were not cured by the end of this clinical experiment, the clinical experiment's point of termination was treated as truncated data.

\section{Results}

In this clinical experiment, which was performed from December 2012 to January 2014, we evaluated 15 patients with an average $62.95 \pm 16.57$ years (range, 18-82). The two groups had age or gender differences $(P=0.792$ and 0.910 , respectively). No significant difference was seen between groups in in diabetes and hypertension ( $P=0.305$ and 0.851 , respectively). The anatomic distribution and etiology of the pressure ulcers were similar in both groups (Table 2).

Size, volume, and rate changes before and after treatment are described in Table 3. The size change was $-7.23 \pm 13.88$ $\mathrm{cm}^{2}$ in the EG, while it was $-4.28 \pm 8.83 \mathrm{~cm}^{2}$ in the CG. Although there was a larger drop in size in the $E G$ than in the $C G$, the difference was not statistically significant $(P=0.910)$. The rate of size change in $E G$ and $C G$ were $-17.10 \pm 27.16 \%$ and $-18.08 \pm 31.32 \%$, respectively; it was not statistical significance $(P=0.970)$. The changes in volume were also similar, showing a larger decrease in $E G\left(-8.16 \pm 12.09 \mathrm{~cm}^{3}\right)$ than CG $\left(-4.09 \pm 7.66 \mathrm{~cm}^{3}\right)$, but with no statistical significance $(P=0.238)$. The volume change rates were found to be $-32.84 \pm 37.06 \%$ in the EG and $-37.81 \pm 21.64 \%$ in the CG, which shows no significant differences $(P=0.910)$. Alternatively, the volume/size change was significantly greater in the $E G(1.10 \pm 0.78)$ than in the $C G(0.41 \pm 0.30)(P=0.012)$.

For the treatment period-specific changes in size, as compared to the baseline measurements, The EG had a larger decrease in size than the CG during treatment, compared

Table 2. Summary of patients

\begin{tabular}{lcc}
\hline & EG (NPWT+bFGF) & CG (NPWT) \\
\hline Number of patients & 12 & 8 \\
Male & 7 & 5 \\
Female & 5 & 3 \\
Mean age & 61.42 & 65.73 \\
Location & & \\
Sacral area & 9 & 3 \\
Buttock & 0 & 1 \\
Trochanter & 2 & 2 \\
Heel & 1 & 1 \\
Back & 0 & 1 \\
\hline
\end{tabular}


Ahn SK et al.

Combination therapy of NPWT and bFGF

with baseline; the trend was not significant at any of the time points (Table 4, Fig. 1). However, the ulcer volume for the EG in the fourth week was remarkably reduced, compared with baseline. Compared with baselines, volume changes were

Table 3. Comparison of the pre- and post-experiment size and volume changes, change rates and volume/size changes

\begin{tabular}{|c|c|c|c|c|}
\hline \multirow{2}{*}{ Change } & & Experimental group $(n=12)$ & Control group $(n=8)$ & \multirow{2}{*}{ P-value } \\
\hline & & Mean \pm standard deviation & Mean \pm standard deviation & \\
\hline \multirow[t]{2}{*}{ Surface area } & Amount $\left(\mathrm{cm}^{2}\right)$ & $-7.23 \pm 13.88$ & $-4.28 \pm 8.83$ & 0.910 \\
\hline & Rate $(\%)$ & $-17.10 \pm 27.16$ & $-18.08 \pm 31.32$ & 0.970 \\
\hline \multirow[t]{2}{*}{ Volume } & Amount $\left(\mathrm{cm}^{3}\right)$ & $-8.16 \pm 12.09$ & $-4.09 \pm 7.66$ & 0.238 \\
\hline & Rate (\%) & $-32.84 \pm 37.06$ & $-37.81 \pm 21.64$ & 0.910 \\
\hline \multicolumn{2}{|c|}{ Volume/Surface } & $1.10 \pm 0.78$ & $0.41 \pm 0.30$ & $0.012^{*}$ \\
\hline
\end{tabular}

The statistical significance test was performed using the Mann-Whitney $U$ test.

*P-value $<0.05$.

Table 4. The size changes at first, second, third, and fourth week size compared with the baseline

\begin{tabular}{llcccc}
\hline Size change amount & & Baseline - 1 wk & Baseline - 2 wk & Baseline - 3 wk & Baseline - 4 wk \\
\hline Experimental group & Amount $\left(\mathrm{cm}^{2}\right)$ & $0.70 \pm 3.28$ & $-4.08 \pm 7.21$ & $-5.37 \pm 9.14$ & $-5.42 \pm 8.06$ \\
& P-value & 1.000 & 0.0757 & 0.664 & 0.1232 \\
Control group & Amount $\left(\mathrm{cm}^{2}\right)$ & $-0.87 \pm 1.66$ & $-2.35 \pm 6.72$ & $-5.23 \pm 8.33$ & $-4.74 \pm 9.06$ \\
& P-value & 0.0938 & 0.3548 & 0.1192 & 0.1830 \\
\hline
\end{tabular}

The statistical significance test was performed using the paired t-test.

*P-value $<0.05$.

Table 5. The volume changes at first, second, third, and fourth week compared with the baseline

\begin{tabular}{llcccc}
\hline Volume change amount & & Baseline - 1 wk & Baseline - 2 wk & Baseline - 3 wk & Baseline - 4 wk \\
\hline Experimental group & Amount $\left(\mathrm{cm}^{2}\right)$ & $-0.18 \pm 1.29$ & $-4.85 \pm 7.42$ & $-5.53 \pm 8.51$ & $-6.30 \pm 10.81$ \\
& P-value & 0.6284 & $0.0049^{*}$ & $0.0049^{*}$ & $0.0161^{*}$ \\
\multirow{2}{*}{ Control group } & Amount $\left(\mathrm{cm}^{2}\right)$ & $-0.36 \pm 0.94$ & $-2.34 \pm 5.36$ & $-4.05 \pm 7.66$ & $-4.22 \pm 7.59$ \\
& P-value & 0.4375 & 0.0781 & $0.0078^{*}$ & $0.0078^{*}$ \\
\hline
\end{tabular}

The statistical significance test was performed using the paired t-test. Values are means \pm SD.

*P-value $<0.05$.

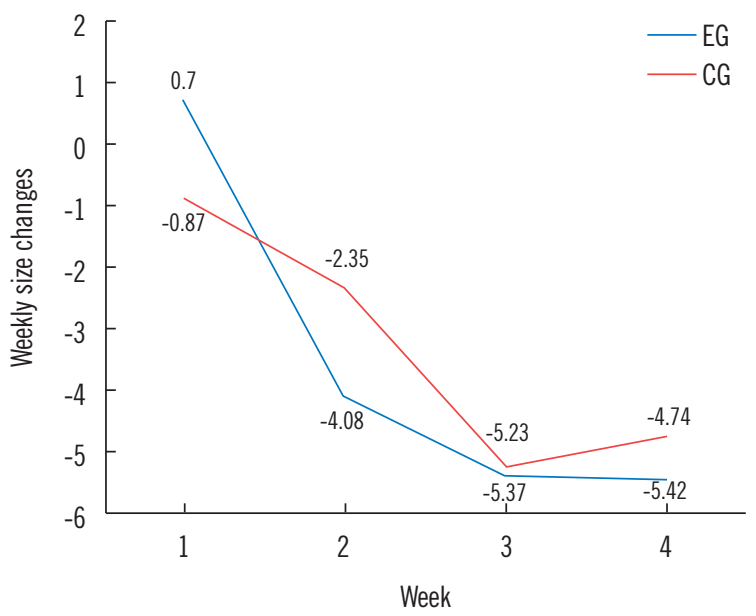

Fig. 1. Baseline and weekly size changes.

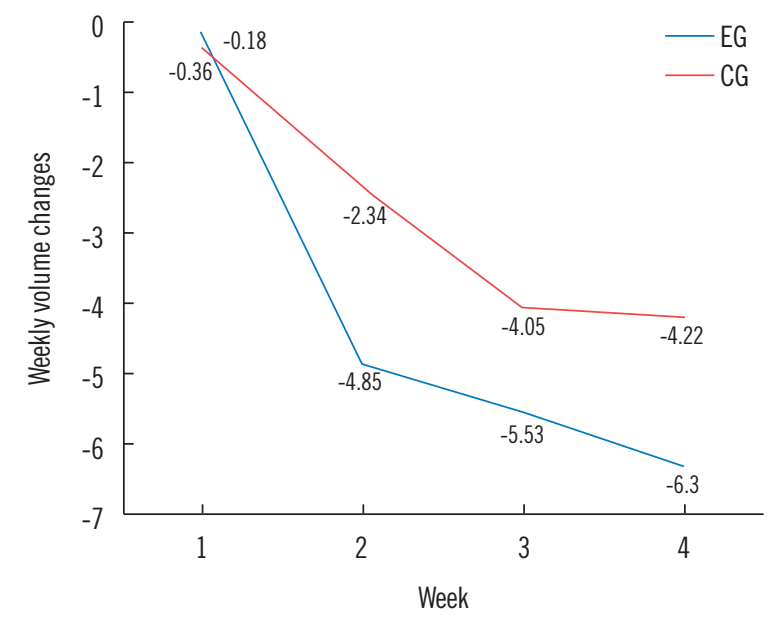

Fig. 2. Baseline and weekly volume changes. 
Ahn SK et al.

Combination therapy of NPWT and bFGF
Table 6. Ratio of patients experiencing pressure ulcer volume reduction of at least $50 \%$ after treatment (\%)

\begin{tabular}{lccc}
\hline Percentage & $\begin{array}{c}\text { Experimental group } \\
(n=12)\end{array}$ & $\begin{array}{c}\text { Control group } \\
(n=8)\end{array}$ & P-value \\
\hline$\geq 50 \%$ & $5(42 \%)$ & $2(25 \%)$ & 0.444 \\
$<50 \%$ & $7(58 \%)$ & $6(75 \%)$ & \\
\hline
\end{tabular}

The statistical significance test was performed using a Chi-square test.

*P-value $<0.05$.

statistically significant during the second, third, and fourth week for the EG ( $P=0.0049,0.0049$, and 0.0161, respectively), and the third and fourth weeks for the $C G(P=0.0078$ and 0.0078 , respectively) (Table 5, Fig. 2).

Forty-two percent of the EG showed a decrease in the ratio of patients who experienced at least a $50 \%$ decrease in pressure ulcer volume at week four, compared with the baseline; $25 \%$ of the CG had a decrease. Although the EG had a higher ratio, it was not statistically significant $(P=0.444$, Table 6$)$.

Table 7 and Fig. 3 describe the duration of a 50\% decrease in a pressure ulcer, compared with baseline. The EG took $20.42 \pm 2.64$ days to reduce the pressure ulcer by $50 \%$ or more, while the $C G$ took $24.50 \pm 2.17$ days. This finding indicates that the EG recovered faster, though the difference was not statistically significant $(P=0.377)$. During the experiment period, no subjects showed abnormal vital signs or clinically abnormal reactions in either group.

\section{Discussion}

Different tissues have different pressure tolerance levels. Muscles are more vulnerable to pressure-caused ischemia than skin [2]. It is not clear how a pressure ulcer is caused. One hypothesis is that pressure ulcers develop from the bone to the surface of skin. Such a hypothesis could explain how each tissue has a different critical ischemia time [6]. Another hypothesis is that the skin is first damaged and then moves down inside the skin. Maklebust and Sieggreen call this hypothesis the "top-to-bottom model" [1].

Wound recovery has stages of coagulation, inflammation, proliferation, and remodeling. In this process, various growth factors (e.g., bFGF, platelet-derived growth factor, transforming growth factor beta, and epidermal growth factor) and cytokines are secreted. IL-2b plays an important role in controlling immune responses and inflammatory reactions among the pro-inflammatory cytokines. TNF-alpha, synthesized by monocytes and macrophages, has an important function in
Table 7. Duration for at least $50 \%$ reduction in the pressure ulcer compared with the baseline (days)

\begin{tabular}{lccc}
\hline Percentage & $\begin{array}{c}\text { Experimental group } \\
(n=12)\end{array}$ & $\begin{array}{c}\text { Control group } \\
(n=8)\end{array}$ & P-value \\
\hline$\geq 50 \%$ & $20.42 \pm 2.64$ & $24.50 \pm 2.17$ & 0.377 \\
\hline
\end{tabular}

The statistical significance test was performed using a log-rank test. Values are means $\pm S D$.

${ }^{*}$ P-value $<0.05$.

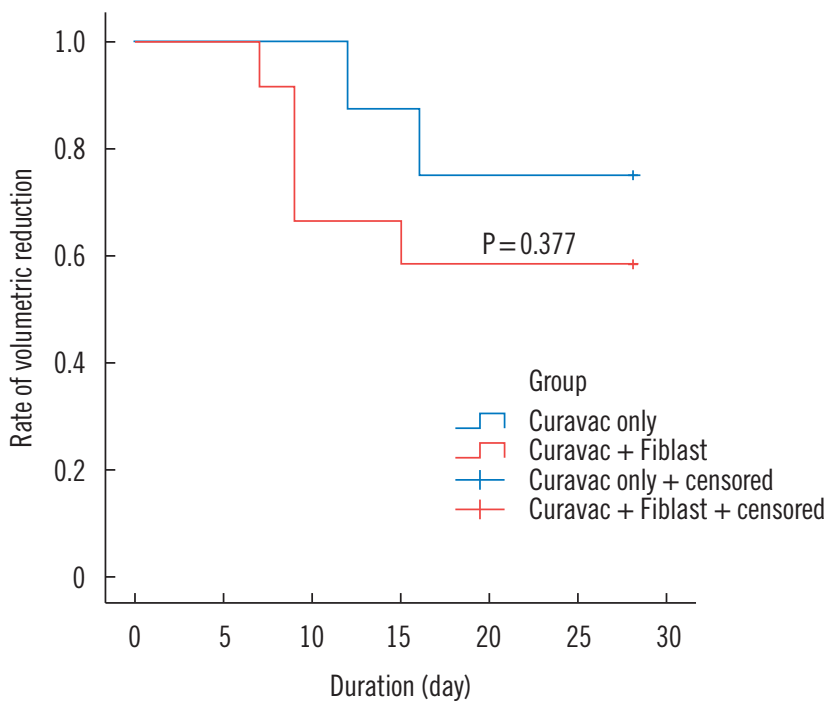

Fig. 3. Comparison of the volumetric reduction rate between the EG (NPWT+bFGF) and the CG (NPWT).

the human physical reaction to diverse inflammatory diseases and infections [10]. VEGF and VEGFR-2 (KDR) promote angiogenesis, as well as the mobility and growth of endothelial cells. FGF2 (bFGF) and bFGFR are involved in angiogenesis, cell growth and differentiation, and facilitate fibroblast growth, neovascularization, and granulation tissue formation [14]. As such, wound recovery requires diverse growth factors.

The bFGF, an important growth factor for wound recovery, is a human recombinant form that was first commercialized in Japan in 2001 [15]. Since then, it has been widely used to treat patients with pressure ulcers, burns, and ulcer wounds in the leg. Multiple studies have confirmed the efficacy of bFGF. However, only a few studies have assessed bFGF with pressure ulcer wounds. Our study was based on the hypothesis that the pressure ulcer wound would recover faster if bFGF was applied, because it has reduced bFGFR and other growth factors. We also sought to investigate the efficacy of combination therapy with bFGF and NPWT in patients with pressure ulcer wounds based on a study reported that VEGF, 
EGF, platelet-derived growth factor, and angiotensin-2 rose significantly after using NPWT [16].

There are many controversies regarding the best method for measuring wound size and volume, and diverse methods have been introduced. Measuring wound length and width is simple, but it can be difficult to apply to large wounds or wounds with irregular shapes. The tracing or planimetry method measures a wound by placing a permeable metric grid on it and counting the number of quadrangles. It is easy and reproducible, but it there are issues with tracing. There are also errors when determining whether to include halfquadrangles [17]. The Kundin device consists of disposable, 3D, and plastic-coated paper gauze. The device can be used to measure wound length and width. The Kundin device is not expensive and does not take a long time to use. However, it must be placed on the wound, which can cause pain [18]. A computer program called Verge Videomater (VeV) (Vista medical, Winnipeg, Canada) is also available. The program measures wounds using digital photographs. It is highly reproducible and avoids direct contact with the wound [19]. Stereophotogrammetry (SPG) is similar to VeV. However, the former can superimpose photographs and extract 3D images through stereogram processes. Cutler et al. reported that the tracing method and photo method were similar $(r=0.98$, $\mathrm{P}<0.001$ ). Thomas and Wysocki [20] stated that tracing was most accurate one among the 2D method of acetate tracings, the photograph methods, and the Kundin gauge methods. Griffin et al. [21] argued that there were no differences between the photograph and transparency methods. In another study, SPG was said to be the most accurate and reproducible [19,22]. Langemo et al. [19] examined SPG, Kundin gauze, planimetry tracing, and a ruler, and found that the most erroneous method was using the ruler length and width, but it was the most accurate method after SPG. Keast et al. [23] contended that the ruler method, which measured the longest width and longest length of a wound with a ruler, was the most appropriate and reproducible. As a result, we chose the ruler method. The ruler method is easy to apply, inexpensive, and does not require any special techniques to be performed by the medical staff [13].

We confirmed that no significant differences in therapeutic effects between previous reports and our results. As shown in Table 3, the rate of change in surface area reduction was $-17.10 \pm 27.16 \%$ for the $E G$ and $-18.08 \pm 31.32 \%$ for the CG. These rates are similar to the results from the trials using $\mathrm{VAC}^{\circledR}$. Braakenburg et al. [24] examined 65 cases and found an average size reduction of $-14.24 \%$. Eginton et al. [25] investigated seven cases and found a $-16.4 \%$ size reduction, which is similar to our results. As for the rate of change in the volume in Table 3, the reduction rates for the EG and CG were $-32.84 \pm 37.06 \%$ and $-37.81 \pm 21.64 \%$, respectively. These results are also consistent with the results of the trials using VAC ${ }^{\circledR}$. Ford et al. [26], Wanner et al. [5], and Eginton et al. [25] reported mean reductions of $-51.8 \%$ in 41 cases, $-55.0 \%$ in 22 cases, and $-59.0 \%$ in 7 cases, respectively. The CG also experienced a sufficiently accelerated wound recovery process, as shown in this study.

No significant differences were found between the groups with regard to the four values derived from the measured amount of changes and calculated change rates in the surface area and volume (Table 3). These results may lead to the assumption that the use of bFGF did not greatly influence pressure ulcer therapy outcomes. However, the volume/size change in the $E G$ was $1.10 \pm 0.78$, while in the $C G$ it was $0.41 \pm 0.30$ and the difference was statistically significant $(P=0.012)$. This implies that the combined use of bFGF and NPWT could cause more change in pressure ulcer wound volume than the use of NPWT by itself. Since muscles require more oxygen than skin, and thus are more prone to ischemia, most of the pressure ulcer cases have a deep inner wound. For this reason, most of the pressure ulcer cases have inner pockets. This is why volume matters more than size when managing a pressure ulcer.

The treatment period-specific size and volume changes in each group are organized in Tables 4 and 5, and Figs. 1 and 2. These tables show the experiment results regarding significant change rates, compared with the baseline, at each treatment point. There were no differences in size according to the period, but significant differences were found in the CG's third and fourth week results and the EG's second, third, and fourth week results. Based on these data, combination of bFGF and NPWT is more effective in terms of volume change than size change. Also, the results imply that the combination treatment could help reduce pressure ulcer volume faster than the use of NPWT by alone.

Table 7 and Fig. 4 give the time cost for a 50\% reduction in pressure ulcer volume. The EG took $20.42 \pm 2.64$ days to reduce the volume of the pressure ulcer by $50 \%$ or more, while the CG took $24.50 \pm 2.17$ days to accomplish the same. Though this difference was not statistically significant, the pressure ulcer volume reduction was four days faster in the EG. With regard to reaching $50 \%$ of the initial wound volume, 
Wanner et al. [5] reported a mean time of 27 days in 11 patients treated with $\mathrm{VAC}^{\circledR}$ versus 28 days in 11 patients in the control group $(P=0.9)$. Both groups in our research showed better performances than those in Wanner et al.

This study was conducted to investigate the effects of Curavac $^{\circledR}$ and Fiblast ${ }^{\circledR}$. VAC ${ }^{\circledR}$ (Kinetic Concepts, Inc., San Antonio, TX, USA) is one of the most commonly used NPWT devices in the world. A number of studies have proved the superior wound healing efficacy of $\mathrm{VAC}^{\circledR}$, compared with the standard wound therapy [16]. In South Korea, the Curavac ${ }^{\circledR}$ wound dressing kit, manufactured by Daewoong Pharmaceutical Co., Ltd., is also used as an NPWT device. Despite the clinically observed superior efficacy of Curavac $^{\circledR}$ for rapid wound healing compared with the standard wound therapy, to our knowledge, no study documenting this fact has yet been published. Therefore, this study was conducted to provide data to support the efficacy of Curavac $^{\circledR}$ and to investigate the effectiveness of Fiblast ${ }^{\circledR}$.

Collectively, the combined use of NPWT and bFGF provided better results than the use of NPWT alone in pressure ulcer volume reduction. It has been reported that there was a significant increase in VEGF, EGF, PDGF, and angiotensin-2 following NPWT, while bFGF was decreased significantly [16]. Since bFGF plays crucial roles in wound healing, supplementing the growth factor can be beneficial on pressure ulcer care, confirming the superior effect of combination therapy in patients with pressure ulcers.

Pressure ulcers are chronic wounds and tend to form a deep inner wound even though its surface is small. Therefore, a change in the pressure ulcer volume is a key indicator for recovery. NPWT increases various growth factors to accelerate the wound recovery process. We found that pressure ulcer treatment based solely on NPWT was statistically significant, while the combined use of NPWT and bFGF contributed even more to the reduction of the pressure ulcer volume. This finding indicates that NPWT is highly efficacious in decreasing the vertical dimension of a pressure ulcer. Moreover, bFGF plays a role in accelerating a larger decrease in volumes in pressure ulcers. The size reduction, however, was found to be statistically insignificant in this research, and this is likely due to the polyurethane foam applied in the NPWT. The sites of pressure sores, nutrition compounds, and underlying diseases could be biases. Thus, further study is expected to overcome such a bias.

\section{Conflict of interest}

All named authors hereby declare that they have no conflicts of interest to disclose.

\section{Acknowledgement}

This work was supported by the Soonchunhyang University Research Fund.

\section{References}

1. Maklebust J. Pressure ulcers: etiology and prevention. Nurs Clin North Am 1987;22:359-77.

2. Amlung SR, Miller WL, Bosley LM. The 1999 National Pressure Ulcer Prevalence Survey: a benchmarking approach. Adv Skin Wound Care 2001;14:297-301.

3. VanGilder $C$, Amlung $S$, Harrison P, et al. Results of the 2008-2009 International Pressure Ulcer Prevalence Survey and a 3-year, acute care, unit-specific analysis. Ostomy Wound Manage 2009;55:39-45.

4. Isago T, Nozaki M, Kikuchi Y, et al. Negative-pressure dressings in the treatment of pressure ulcers. J Dermatol 2003;30: 299-305.

5. Wanner MB, Schwarzl F, Strub B, et al. Vacuum-assisted wound closure for cheaper and more comfortable healing of pressure sores: a prospective study. Scand J Plast Reconstr Surg Hand Surg 2003;37:28-33.

6. Gupta S, Baharestani M, Baranoski S, et al. Guidelines for managing pressure ulcers with negative pressure wound therapy. Adv Skin Wound Care 2004;17 Suppl 2:1-16.

7. Marks MW, Argenta LC, Thornton JW. Rapid expansion: experimental and clinical experience. Clin Plast Surg 1987;14: 455-63.

8. Morykwas MJ, Argenta LC, Shelton-Brown El, et al. Vacuumassisted closure: a new method for wound control and treatment: animal studies and basic foundation. Ann Plast Surg 1997;38:553-62.

9. Suissa D, Danino A, Nikolis A. Negative-pressure therapy versus standard wound care: a meta-analysis of randomized trials. Plast Reconstr Surg 2011;128:498e-503e.

10. Gospodarowicz D. Localisation of a fibroblast growth factor and its effect alone and with hydrocortisone on 3T3 cell growth. Nature 1974;249:123-7.

11. Tanaka E, Ase K, Okuda T, et al. Mechanism of acceleration of wound healing by basic fibroblast growth factor in geneti- 
cally diabetic mice. Biol Pharm Bull 1996;19:1141-8.

12. Black J, Baharestani MM, Cuddigan J, et al. National Pressure Ulcer Advisory Panel's updated pressure ulcer staging system. Adv Skin Wound Care 2007;20:269-74.

13. Xakellis GC Jr, Frantz RA. Pressure ulcer healing: what is it? What influences it? How is it measured? Adv Wound Care 1997;10:20-6.

14. Motomura H, Ohashi N, Harada T, et al. Aggressive conservative therapy for refractory ulcer with diabetes and/or arteriosclerosis. J Dermatol 2006;33:353-9.

15. Ichioka S, Ohura N, Nakatsuka T. The positive experience of using a growth factor product on deep wounds with exposed bone. J Wound Care 2005;14:105-9.

16. Xia CY, Yu AX, Qi B, et al. Analysis of blood flow and local expression of angiogenesis associated growth factors in infected wounds treated with negative pressure wound therapy. Mol Med Rep 2014;9:1749-54.

17. Thawer HA, Houghton PE, Woodbury MG, et al. A comparison of computer-assisted and manual wound size measurement. Ostomy Wound Manage 2002;48:46-53.

18. Kundin JI. Designing and developing a new measuring instrument. Perioper Nurs Q 1985;1:40-5.

19. Langemo DK, Melland H, Hanson D, et al. Two-dimensional wound measurement: comparison of 4 techniques. Adv Wound Care 1998;11:337-43.

20. Thomas AC, Wysocki AB. The healing wound: a comparison of three clinically useful methods of measurement. Decubitus 1990;3:18-20, 4-5.

21. Griffin JW, Tolley EA, Tooms RE, et al. A comparison of photographic and transparency-based methods for measuring wound surface area. Phys Ther 1993;73:117-22.

22. Bulstrode CJ, Goode AW, Scott PJ. Stereophotogrammetry for measuring rates of cutaneous healing: a comparison with conventional techniques. Clin Sci (Lond) 1986;71:437-43.

23. Keast DH, Bowering CK, Evans AW, et al. MEASURE: A proposed assessment framework for developing best practice recommendations for wound assessment. Wound Repair Regen 2004;12:S1-17.

24. Braakenburg A, Obdeijn MC, Feitz R, et al. The clinical efficacy and cost effectiveness of the vacuum-assisted closure technique in the management of acute and chronic wounds: a randomized controlled trial. Plast Reconstr Surg 2006;118: 390-7; discussion 8-400.

25. Eginton MT, Brown KR, Seabrook GR, et al. A prospective randomized evaluation of negative-pressure wound dressings for diabetic foot wounds. Ann Vasc Surg 2003;17:6459.

26. Ford CN, Reinhard ER, Daniel BS, et al. Interim Analysis of a Prospective, Randomized Trial of Vacuum-Assisted Closure Versus the Healthpoint System in the Management of Pressure Ulcers,Ann Plast Surg 2002;49:55-61. 